\title{
Scientific Rationality: Phlogiston as a Case Study
}

\author{
Jonathon Hricko*
}

Penultimate Draft - Please cite the published version, which appears in Tzu-Wei Hung \& Timothy Lane (Eds.). (2017). Rationality: Constraints and Contexts. Elsevier Academic Press, London.

\begin{abstract}
I argue that it was rational for chemists to eliminate phlogiston, but that it also would have been rational for them to retain it. I do so on the grounds that a number of prominent phlogiston theorists identified phlogiston with hydrogen in the late eighteenth century, and this identification became fairly well-entrenched by the early nineteenth century. In light of this identification, I critically evaluate Hasok Chang's argument that chemists should have retained phlogiston, and that doing so would have benefited science. I argue that these benefits would have been unlikely, and I go on to consider some more likely benefits and harms of retaining phlogiston. I conclude that there is a sense in which scientific rationality concerns what is permissible, as opposed to what is required, so that retention and elimination may, at least sometimes, both be rationally permissible options.
\end{abstract}

Keywords: Scientific Rationality, Chemical Revolution, Phlogiston, Hydrogen, Humphry Davy

\section{Introduction}

The Chemical Revolution, to a first approximation, was an event that took place in the late eighteenth century, and involved chemists embracing Antoine

*Education Center for Humanities and Social Sciences, National Yang-Ming University, email: jonathon [dot] hricko [at] gmail [dot] com. 
Lavoisier's oxygen theory and abandoning phlogiston-based explanations of various phenomena. The phenomena in question included combustion and the transformation of metals into oxides. For some time, chemists explained these phenomena by appealing to a substance they called phlogiston, which they posited as a component of inflammable substances and metals. According to those explanations, when an inflammable substance undergoes combustion, it loses its phlogiston; and when a metal is changed into an oxide, it loses its phlogiston. But in the late eighteenth century, Lavoisier did away with phlogiston, and explained these phenomena in terms of oxygen. Before long, the community of chemists, as a whole, followed Lavoisier, and they eliminated phlogiston from chemistry and embraced the oxygen theory.

Today, the literature on the Chemical Revolution is so voluminous that it's difficult to say anything that hasn't already been claimed by some scholar, and contested by another. Indeed, the first approximation that I offered in the previous paragraph would be unacceptable to different scholars for different reasons. ${ }^{1}$ Considering the breadth of the literature on the Chemical Revolution, one might suspect that nothing remains to be said about it. Hasok Chang's recent work, however, shows that this is not the case. Perhaps the most exciting aspect of Chang's work concerns the bold and original conclusion for which he argues, namely, that phlogiston was killed prematurely. More specifically, Chang's view is that chemists should have retained phlogiston, just as they did oxygen, and that science could have benefited from this pluralistic approach.

Chang recognizes that his re-telling of the story of the Chemical Revolution bears on the issue of rationality. Although he holds that the Chemical Revolution "was a fairly rational affair," he locates an element of irrationality, not in the chemists who continued to hold on to phlogiston, but in those who embraced Lavoisier's oxygen theory too readily (2012, p. 56). On Chang's understanding of rationality, if one were to admit the rationality of the response of these latter chemists, this admission would threaten Chang's claim that phlogiston was killed too soon (2012, p. 51).

In this chapter, I will examine and critically evaluate the arguments that Chang puts forward in favor of his view that chemists should have retained phlogiston. My aim in doing so is two-fold - in short, I hope to shed some light on the Chemical Revolution in particular, and on scientific rationality

\footnotetext{
${ }^{1}$ To take one example, Klein (2015) argues that the changes that Lavoisier inaugurated shouldn't be understood as constituting a revolution at all.
} 
more generally. Regarding the former, I take it that Chang is correct that it would have been rational for chemists to retain phlogiston, though my way of supporting this claim will differ from Chang's. My view will differ from Chang's in another respect, insofar as I will defend the claim that it was also rational for chemists to eliminate phlogiston. On my view, then, both the decision to retain phlogiston and the decision to eliminate it would have been rational, and the rationality of eliminating phlogiston needn't threaten Chang's claim that it would have been rational for chemists to retain it. My second aim is to use this view of the Chemical Revolution to illustrate something about scientific rationality more generally, namely, that there is a sense in which it concerns what is permissible, as opposed to what is required. When it comes to deciding whether to retain or eliminate a given entity, there are cases (like that of phlogiston) in which both options are rationally permissible.

To that end, I'll proceed as follows. In section 2, I'll summarize Chang's reasons for thinking that phlogiston suffered a premature death, and that science could have benefited if chemists had retained it. In section 3, I'll argue that it's likely that the retention of phlogiston would not have led to the benefits that Chang discusses. These benefits would have been unlikely because a number of chemists identified phlogiston with hydrogen in the late eighteenth century, and, as I will argue, this identification became rather well-entrenched by the early nineteenth century. It's likely that retaining phlogiston after this point would have brought about mixed results. It could have benefited science in ways that Chang does not discuss, but it could also have retarded scientific progress in other ways. In section 4, I'll use the identification of phlogiston with hydrogen in order to draw some conclusions about the rationality of the Chemical Revolution. I'll argue that it would have been rational for chemists to eliminate phlogiston once they found that various substances thought to be rich in phlogiston contain no hydrogen. On the other hand, I'll argue that this identification could also have supported the rationality of retaining phlogiston, since, insofar as it was rational to retain hydrogen, it would have been rational to retain phlogiston. Finally, in section 5, I'll draw some conclusions about scientific rationality more generally. 


\section{Chang on Retaining Phlogiston}

In his recent work on the Chemical Revolution, Chang claims that phlogiston was killed prematurely, and that retaining it could have benefited science. ${ }^{2}$ Contrary to what many historians and philosophers have held, he argues that the Chemical Revolution did not consist in a quick conversion of the vast majority of late-eighteenth-century chemists to Lavoisier's oxygen theory. As Chang emphasizes, there were, in fact, many anti-Lavoisierians who continued to entertain the phlogiston theory well into the nineteenth century (2010, pp. 62-68; 2012, pp. 29-34). Chang's claim, then, is that even after we take this into account, the death of phlogiston was still premature.

Chang's arguments for this claim come in four varieties. First of all, he argues that the elimination of phlogiston resulted in the elimination of "certain valuable scientific problems and solutions" (2012, p. 47). Chang's central example is familiar from discussions of so-called 'Kuhn loss.' 3 While phlogiston theorists provided an explanation of the similarity of the metals in terms of their shared phlogiston, oxygen theorists not only failed to provide a solution, but ignored the very problem that the phlogiston theorists had attempted to solve $\left(2012\right.$, pp. 21, 43-44). ${ }^{4}$ The retention of phlogiston, then, would have served as a reminder of certain problems and purported solutions.

Secondly, Chang argues that there were productive interactions between oxygen and phlogiston that could have continued if the latter had been retained (2012, pp. 48-50). He points out that it's unlikely that Lavoisier could have achieved what he did without building upon work by phlogiston theorists like Joseph Priestley and Henry Cavendish. Chang sees no reason why such productive interactions would have ceased if phlogiston had been retained.

Thirdly, Chang argues that the elimination of phlogiston "close[d] off certain theoretical and experimental avenues for future scientific work" (2012, p. 47). More specifically, he argues that, if chemists had retained phlogiston

\footnotetext{
${ }^{2}$ Chang is thus consciously engaging in counterfactual history of science (2012, pp. 62 $65)$, and he thus advocates the view that the results of science are contingent as opposed to inevitable (2012, p. 288). In this chapter, I'll follow him in both of these respects. For more on counterfactual history, see Radick (2008) and Reiss (2009). For more on whether the results of science are contingent or inevitable, see Soler (2008) and Kinzel (2015).

${ }^{3}$ For Kuhn's own discussion of this example, see Kuhn (2012/1962, p. 156).

${ }^{4}$ When I write of the phlogiston theorists, I don't mean to imply that all such theorists defended the same theory. In fact, they often defended distinct and mutually incompatible phlogiston theories, some of which I will discuss in section 3.1.
} 
alongside oxygen, it would have been possible to make more rapid progress in theorizing about electricity and energy. These productive interactions, in turn, lend support to Chang's more general advocacy of pluralism in science, which involves maintaining competing systems, and his rejection of monism, which involves the elimination of all competing systems except for the 'winner' (2011, pp. 425-428; 2012, ch. 5).

Fourthly, Chang argues that, by the early nineteenth century, phlogiston and oxygen were on more-or-less equal footing, theoretically speaking. What justified chemists in retaining oxygen was really the set of operations on which they relied in carrying out various experiments. This justification, in Chang's view, would have applied equally well to phlogiston (2011, p. 420).

These latter two arguments are the most important for my purposes in the remainder of the chapter, and so I'll now turn to a more detailed discussion of each of these arguments.

\subsection{Phlogiston, Electricity, and Energy}

Chang claims that the elimination of phlogiston resulted in the elimination of various theoretical and experimental possibilities that would have been beneficial for scientists to pursue. ${ }^{5}$ More specifically, he believes that, by retaining phlogiston, scientists could have made more rapid progress regarding electricity, on the one hand, and energy, on the other. According to Chang, if we were to engage in some truly whiggish history of science, there are two entities with which we would identify phlogiston, namely, free electrons and chemical potential energy (2009, pp. 246-250; 2011, pp. 412-423; 2012, pp. 43-48).

To begin with, there is the identification with free electrons. In Chang's view, the phlogiston theorists were correct that metals are similar to one another by virtue of some shared constituent, and that this constituent is the same thing that is released in combustion. As it turns out, it is free electrons. This isn't just a post hoc identification because, as Chang points out, many phlogiston theorists, some of whom I will discuss in more detail in section 3.1, posited a connection between phlogiston and electricity. They did so, not merely out of a desire to have a grand unified theory of all of the imponderable fluids, of which phlogiston and electricity were two, ${ }^{6}$ but for experimental

\footnotetext{
${ }^{5}$ It's worth noting that he thinks these benefits have since been realized "by some very circuitous routes" without phlogiston $(2012$, p. 47$)$.

${ }^{6}$ Or three, if one prefers a two-fluid theory of electricity.
} 
reasons as well. For example, Chang notes that it was known that electricity could be used to change calxes (which we know as the oxides of metals) into metals, a process that phlogiston theorists understood in terms of gain in phlogiston. He claims that if phlogiston had been retained, along with its posited connection with electricity, chemists would have continued to use any methods that they could think of in order to isolate it. He argues that it's therefore not unreasonable to think that various electrical phenomena could have been uncovered sooner. And he even speculates that, if phlogiston had been retained, the discovery of the electron might have been taken for the discovery of phlogiston.

Chang also argues that, if it had been retained, the concept of phlogiston would have been split, in which case it would also have been identified with chemical potential energy. His claim is that gain and loss of phlogiston can be understood in terms of gain and loss of potential energy, and that retaining phlogiston could have contributed to more rapid progress being made regarding energy. Insofar as phlogiston was conceived of as a principle, as opposed to a component, and insofar as it was conceived of as an imponderable fluid, the phlogiston theorists had a way of tracking what we would now classify as energy considerations. The oxygen theorists, on the other hand, did not. In accordance with the idea of the conservation of matter, they focused on the weights of substances before and after chemical reactions had taken place, and gain and loss of energy is not something that one can keep track of in this way.

\subsection{Phlogiston Was Not Any Worse Than Oxygen}

Chang also argues that, in light of the fact that oxygen and phlogiston were on more-or-less equal footing by the early nineteenth century, it would have been rational to retain the latter as well as the former. In order to understand his argument, we must first look at Lavoisier's oxygen in a bit more detail.

As Chang emphasizes, by the early nineteenth century, almost every theoretical claim that Lavoisier made about oxygen was proven to be false (2011, pp. 415-420; 2012, pp. 8-10). ${ }^{7}$ Lavoisier's oxygen theory was a theory of combustion, among other things. He explained the heat and light that result from combustion in terms of the decomposition of oxygen gas, which

\footnotetext{
${ }^{7}$ Chang draws support from similar claims made by McEvoy (1997, pp. 22-23) and Siegfried (1988, p. 35).
} 
involves the separation of oxygen base from caloric. By the early years of the nineteenth century, this explanation was found wanting. If oxygen gas is supposed to be the sole supporter of combustion, then Lavoisier needed an explanation for why other gases, all of which contain caloric combined with some base or other, do not support combustion. Even more damning is the fact that chemists found instances of combustion that do not involve oxygen gas at all, and so the latter could not be the sole supporter of combustion. The oxygen theory was not just a theory of combustion, though - it was also a theory of acidity. For Lavoisier (1965/1789, p. 65), oxygen was the principle of acidity, that which renders the substances with which it combines acidic. But by 1810, Humphry Davy had shown the falsity of the oxygen theory of acidity by showing that muriatic acid (hydrochloric acid, $\mathrm{HCl}$ ) contains no oxygen.

In light of all of these theoretical failures, one might well wonder why oxygen was retained at all. Chang's answer is that the meaning of 'oxygen' can, at least in part, be fixed operationally in such a way that there is continuity from Lavoisier's time to our own (2011, p. 419). His basic idea is that all of the operations by which Lavoisier produced oxygen gas work just as well today as they did in the late eighteenth century.

Returning now to the case of phlogiston, Chang's claim is that we can tell essentially the same story. Even in light of various theoretical failures, there is operational continuity. For example, Priestley proposed to produce phlogis-

ton by converting metals into calxes. Although today, we would understand this reaction in terms of converting metals into oxides, the operations are the same. And we can fix the meaning of 'phlogiston' operationally, in terms of what is produced when a metal is converted to a calx. Chang uses these considerations in order to conclude that "there was no convincing reason for chemists to kill phlogiston in the late eighteenth century - at least no more convincing reason than there was to kill oxygen in the early nineteenth century" (2011, p. 420).

\section{Evaluating the Benefits of Retaining Phlo- giston}

I find much with which to agree in Chang's work on the Chemical Revolution, and in the remainder of the chapter, I'll indicate some of these points of 
agreement. My primary goal in this section, however, is to argue that, if phlogiston had been retained, the benefits that Chang points to regarding electricity and energy would likely not have materialized. My argument hinges on the fact that a number of phlogiston theorists in the late eighteenth century identified phlogiston with hydrogen. I'll attempt to support the claim that this identification was rather well entrenched by the early nineteenth century. And I'll argue that, as a result, retaining phlogiston would most likely have brought about mixed results. It could have brought about some benefits that Chang does not discuss, but it could have retarded progress in various ways as well.

\subsection{Phlogiston and Hydrogen}

In the later years of the eighteenth century, a number of prominent phlogiston theorists identified phlogiston with inflammable air, which we now call hydrogen. ${ }^{8}$ Cavendish was perhaps the first to make this identification. In the course of reporting the effects of various acids on various metals, he writes that "their phlogiston flies off, without having its nature changed by the acid, and forms the inflammable air" (1766, p. 145). And as early as 1782, Priestley makes this identification in a letter to Josiah Wedgwood, in which Priestley describes an experiment that, in his view, "seems to prove, that what we have called phlogiston is the same thing with inflammable air in a state of combination with other bodies" (in Bolton, 1892, p. 33).

While Cavendish may have been the first to make the identification, Richard Kirwan arguably did more than any other phlogiston theorist to defend it. ${ }^{9}$ He first proposes this identification in the notes that he provided for the English translation of Carl Wilhelm Scheele's Chemical observations and experiments on air and fire. He writes of phlogiston's "properties in its purest state; which I take to be that of inflammable Air from metals" (in Scheele, 1780, p. 233). As such, Kirwan's view contrasts with that of Scheele, who claims that "Phlogiston is a true element and a simple principle" (1780, p. 103), but stops short of identifying it with inflammable air, which he claims "is composed of heat and phlogiston" (1780, p. 180). Two years later, Kirwan went on to develop the view that phlogiston and inflammable air are the solid and gaseous states, respectively, of the same substance. He writes:

\footnotetext{
${ }^{8}$ For a detailed discussion of this identification, see Stewart (2012).

${ }^{9}$ Boantza (2008, p. 332) emphasizes Kirwan's contribution in this regard, and dismisses Cavendish's earlier identification as a "fleeting observation" and an "isolated instance."
} 
phlogiston .... can never be produced in a concrete state, single and uncombined with other substances; for the instant it is disengaged from them, it appears in a fluid and elastic form, and is then commonly called inflammable air. (1782, pp. 195-196)

Some time later, in a striking passage from his Essay on phlogiston and the constitution of acids, Kirwan writes that "inflammable air, before its extrication from the bodies in which it exists in a concrete state, was the very substance to which all the characters and properties of the phlogiston of the ancient chymists [sic] actually belonged" (1789, pp. 4-5).

After identifying phlogiston with inflammable air in his Essay, Kirwan goes on to claim that this identification is not an idiosyncrasy of his phlogiston theory, but that it has "met the approbation of the most distinguished philosophers, both at home and abroad" $(1789$, p. 5). He goes on to list a number of phlogiston theorists who, he claims, also accept this identification, including "Dr. Priestley, Mr. Bewly, Mr. Bergman, Mr. Morveau, De La Metherie, Chaptal, Crell, Wiegleb, Westrumb, Hermstadt, Kaersten, \&c." (1789, p. 5). To take one example from this list, Torbern Bergman puts forward a view that looks very much like Kirwan's. He writes:

This principle, when in combination, and then it is properly called phlogiston, may be set loose by various methods; having recovered its elasticity, and gained an aerial form, by a proper increase of specific heat, it receives the name of inflammable air. (1785, pp. 219-220)

As I'll discuss below, there wasn't any universal agreement among phlogiston theorists regarding this identification, and Priestley and Cavendish in particular went on to propose other views incompatible with it. That said, there was at least some agreement regarding the identification, and a number of prominent phlogiston theorists did, at one time or another, defend it.

The oxygen theorists, on the other hand, identified inflammable air, not with phlogiston, but with hydrogen gas. This identification can be seen in the second edition of Kirwan's Essay, which contains both Kirwan's essay and responses from Lavoisier and his colleagues. In his commentary, Lavoisier writes of Kirwan's view that certain substances "all contain the base of inflammable air, that is to say hydrogene [sic]" (in Kirwan, 1789, p. 22). Lavoisier, in accordance with his caloric theory of heat, thereby identifies the base of inflammable air, i.e., inflammable air minus caloric, with 
hydrogen base. It follows that hydrogen gas, for Lavoisier, is inflammable air.

There were certainly terminological differences between the oxygen theorists and the phlogiston theorists. But we can exploit one of Chang's insights (which I discussed in section 2.2) in order to show a sense in which the late-eighteenth-century phlogiston theorists' identification of phlogiston with inflammable air was also an identification of phlogiston with hydrogen. If Chang is correct, then the meanings of terms like 'phlogiston,' 'inflammable air,' and 'hydrogen gas' are, at least in part, fixed operationally. And if we recognize that the chemists who used these terms produced hydrogen by means of a shared set of operations, it's clear that all parties, regardless of whether they were phlogiston theorists or oxygen theorists, were talking about the same substance, namely, hydrogen. In that case, at the operational level, there's good reason to identify Kirwan's phlogiston with Lavoisier's hydrogen gas (but not hydrogen base). Though, to be sure, neither side made this identification explicitly. Moreover, given that we can produce hydrogen by means of the same set of operations today, we can identify Kirwan's phlogiston with our hydrogen.

My claim is that this identification is significant. But as Chang notes, it was one among many attempts by phlogiston theorists to identify various posits of their theories with various substances. Before arguing for the significance of this identification, it's worth briefly discussing some of these other attempts.

To begin with, as Chang points out, both Priestley and Cavendish also identified inflammable air with phlogisticated water (2012, p. 6). We can see Cavendish's view in the following passage. After stating that "inflammable air is either pure phlogiston, as Dr. PRIESTLEY and Mr. KIRWAN suppose, or else water united to phlogiston," Cavendish writes: "Either of these suppositions will agree equally well with the following experiments; but the latter seems to me much the most likely" (1784, p. 137).

Chang goes on to note a similarity between Cavendish's view and another view, which suggests a link between phlogiston and electricity (2012, pp. 44, 80). On Cavendish's view, water is elementary, inflammable air is phlogisticated water, and oxygen is dephlogisticated water. Then there is Johann Wilhelm Ritter's view, which shares the commitment to elementary water, but holds that inflammable air is negatively electrified water, while oxygen is positively electrified water. If we were to identify phlogiston with negative electricity, Cavendish's and Ritter's views would amount to one and the 
same view. And, indeed, some chemists did put forward views along these lines. Chang discusses Priestley himself, who posited a connection between phlogiston and electricity (2012, pp. 80-82). After discussing a number of experiments, Priestley writes:

These experiments favour the hypothesis of two electric fluids, the positive containing the principle of oxigen [sic], and the negative that of phlogiston. These united to water seem to constitute the two opposite kinds of air, viz. dephlogisticated and inflammable. (1802, p. 202)

Moreover, as Chang notes (2012, p. 80), George Smith Gibbes posits a similar connection when he claims that "[t]he principle of the negative side of the galvanic apparatus resides in all combustible bodies, ... and answers exactly to the Phlogiston of Scheele" (1809, p. 13). And without giving up the identification of phlogiston with inflammable air, Kirwan speculates "that phlogiston, in a state perhaps 100 times rarer than inflammable air, and consequently containing much more fire, may possibly constitute the electric fluid" (1782, p. 210).

In order to evaluate the benefits of retaining phlogiston, the crucial issue comes down to the extent to which the identifications between phlogiston and various substances became entrenched in the practice of chemistry. My claim is that the identification of phlogiston with hydrogen became rather well entrenched, while the other identifications did not. To be sure, a full justification of this claim would require more work than I will do here, which will be limited to the discussion of a single, but important, source of evidence, namely, the work of Humphry Davy, to which I'll now turn.

\subsection{Davy's Phlogistic and Electrochemical Speculations}

Davy's work is important to consider because, as Chang notes, he was one of a number of chemists who engaged in some "relatively maverick attempts to employ phlogiston again for various scientific purposes" (2012, p. 65). And of all the chemists working in the early nineteenth century, Chang singles out Davy as "[p]erhaps the most interesting case of the new generation of anti-Lavoisier chemists" (2012, p. 33). One might suspect that Davy's enthusiasm for phlogiston, combined with his work in electrochemistry, provided the perfect conditions for identifying phlogiston with electricity in a way that 
would become entrenched in the practice of chemistry. Indeed, Chang references Davy's phlogistic speculations with this possibility in mind (2012, p. 80). But Davy, in fact, maintained the identification of phlogiston with hydrogen throughout his work. And oftentimes he doesn't even bother to make this identification explicit to his readers. Such passages provide evidence for the claim that this identification was fairly well entrenched, not just for Davy, but for his audience as well. At this point, I'll briefly discuss Davy's phlogistic and electrochemical speculations in order to make this point clear.

To begin with, as Chang points out, Davy does engage in some speculation regarding phlogiston in his 1807 Bakerian Lecture. Davy writes:

A phlogistic chemical theory might certainly by [sic] defended, on the idea that the metals are compounds of certain unknown bases with the same matter as that existing in hydrogene [sic]; and the metallic oxides, alkalies and acids compounds of the same bases with water ...(1808a, p. 33)

Davy goes on to consider the limitations of such a theory immediately after introducing it. But the fact that he mentions it at all shows that he does display some enthusiasm for phlogiston. This passage is notable for another reason, though - if one did not have the identification of phlogiston with hydrogen in mind when reading this passage, it would be completely unclear why this theory is supposed to be a phlogiston theory. Hence, this passage shows that, at this stage of his thinking, if Davy identified phlogiston with anything, it was with hydrogen. Moreover, it shows that he expected that his audience had made the same identification; otherwise, he would have been more explicit about the identification and the reasons for it.

Davy continues his phlogistic speculations in another paper, published in 1808. After emphasizing the superiority of the oxygen theory, he claims that "the only good arguments in favour of a common principle of inflammability, flow from some of the novel analogies in electrochemical science" (1808b, p. 363). He goes on to spell out what he has in mind:

Oxygene [sic] is the only body which can be supposed to be elementary, attracted by the positive surface in the electrical circuit, and all compound bodies, the nature of which is known, that are attracted by this surface, contain a considerable proportion of oxygene [sic]. Hydrogene [sic] is the only matter attracted by the negative surface, which can be considered as acting the opposite 
part to oxygene [sic]; may not then the different inflammable bodies, supposed to be simple, contain this as a common element? (1808b, p. 363)

If we keep in mind the identification of phlogiston with hydrogen, we can see these "novel analogies" as suggesting a kind of phlogiston theory. And indeed, Davy goes on to identify phlogiston with hydrogen more explicitly later in the paper, when, in the course of speculating on the nature of metals, he writes of "the adherence of their phlogiston or hydrogene [sic]" (1808b, p. 364).

Shortly after this passage, Davy engages in some further speculation, and considers "[o]ther hypotheses [which] might be formed upon the new electrochemical facts, in which still fewer elements than those allowed in the antiphlogistic or phlogistic theory might be maintained" (1808b, p. 368). This way of framing his electrochemical speculations makes it clear that, for Davy, these hypotheses are not elaborations of either the oxygen (i.e., "antiphlogistic") theory or the phlogiston theory. That said, Davy's motivation for engaging in these electrochemical speculations appears to be the same as his motivation for engaging in various phlogistic speculations. Robert Siegfried (1964, pp. 118-119) has argued that Davy entertained various phlogistic theories because of his desire to reduce the number of chemical elements, and the same point applies to the hypotheses that Davy mentions here.

The particular hypothesis that Davy goes on to consider is based on his observations of a coincidence between chemical states and electrical states. Acids, being attracted to the positive surface in an electric circuit, are negative, while the alkalies and inflammable substances are positive. Moreover, acids lose their acidic properties when they are positively electrified, while the alkalies lose their alkaline properties when negatively electrified. Davy concludes that, "[i]n these instances the chemical qualities are shewn to depend upon the electrical powers; and it is not impossible that matter of the same kind, possessed of different electrical powers, may exhibit different chemical forms" (1808b, p. 368). Such a hypothesis, then, would admit fewer elements, since the very same element may exhibit different properties depending on its electrical powers.

In a footnote to this passage (1808b, pp. 368-369), and in some unpublished notes (quoted in John Davy, 1836, pp. 405-406), Davy engages in some additional electrochemical speculation, again with the goal of reducing the number of chemical elements. He considers the idea that water is an element, 
and entertains a view that is the opposite of Ritter's, namely, that hydrogen is positively electrified water, and that oxygen is negatively electrified water. The metals, charcoal, sulphur, phosphorus, and nitrogen are constituted of unknown bases and hydrogen, while the acids, oxides, alkalies, and earths are constituted of unknown bases and oxygen. The elements on this theory, then, are water and these unknown bases.

Given that Davy engaged in these electrochemical and phlogistic speculations, one might expect him to posit some kind of connection between phlogiston and electricity of the kind put forward by Priestley, Gibbes, and Kirwan. Davy's phlogistic and electrochemical speculations both involve the idea that metals and inflammable substances contain hydrogen. And since Davy identifies phlogiston with hydrogen, and since he often makes use of the idea that hydrogen is positively charged, one might expect him to identify phlogiston with some kind of electrical power. But an examination of Davy's work frustrates these expectations. For some time, Davy continued to entertain the phlogistic idea that inflammable bodies contain hydrogen (see, e.g., Davy, 1809, p. 103; 1810a, p. 69). And his electrochemical speculations also appear in subsequent work (see, e.g., Davy, 1810a, p. 62). But Davy never identifies phlogiston with electricity, or indeed with anything other than hydrogen. One plausible explanation for this fact is that, for both Davy and his audience, the identification of phlogiston with hydrogen was already too well entrenched to consider displacing.

At this point, if I've established anything at all, it's that Davy identified phlogiston with hydrogen throughout his phlogistic speculations, and that he wrote as if he expected his audience to have the same identification in mind. While I take it that Davy's work provides evidence for my claim that this identification was, by the early nineteenth century, more well entrenched than any other, I acknowledge that this claim requires additional work to fully support. That said, in the remainder of the chapter, I will take this claim for granted, and see what follows from it. But before moving on, it's worth briefly discussing the shape of the further work required to support this claim, and in doing so, I'll indicate some reasons to be optimistic about the prospects.

As Chang notes, Davy was one of a number of anti-Lavoisierian chemists working in the early nineteenth century (2010, pp. 63-68; 2012, pp. 30-34). A complete justification for my claim would therefore involve looking at these other chemists. Among them are some whom I've already discussed in section 3.1, for example, Ritter, Priestley, and Gibbes. Ritter is unlikely to 
have been able to establish a more well-entrenched identification of phlogiston with something other than hydrogen, since, as Chang points out, his work on elementary water was rejected by most chemists (2012, pp. 87-94). It's not clear that Priestley's posited connection between phlogiston and electricity would have fared any better, since, as Chang notes, it's not clear how much attention his 1802 paper received (2012, p. 82). And while Chang lists Gibbes as one of the anti-Lavoisierians, he does not include Gibbes in a subsequent figure that focuses on "salient figures" from the previously mentioned list (2012, pp. 31, 34). If Chang's judgment regarding salience is correct, Gibbes would not have had the influence necessary to entrench his posited connection between phlogiston and electricity. Chang lists a number of other anti-Lavoisierians, but Davy surely stands out as one of the most prominent and influential. And given his phlogistic and electrochemical speculations, his work is likely the most significant when it comes to supporting my claim regarding the entrenchment of the identification of phlogiston with hydrogen. So although I've only discussed a single source of evidence for my claim, it's a significant one.

\subsection{Benefits and Harms of Retention}

At this point, we can evaluate Chang's claim that, if chemists had retained phlogiston, science could have benefited. If I am right that the identification of phlogiston with hydrogen was well entrenched by the early nineteenth century, then if phlogiston had been retained, so would its identification with hydrogen. And so, if we are to engage in an evaluation of the benefits of retaining phlogiston, we must keep this identification in mind.

To begin with, I think Chang is correct about some of the benefits that he discusses. Even if we keep the identification of phlogiston with hydrogen in mind, it's likely that the retention of phlogiston would have served as a useful reminder of unsolved problems and potential solutions. Chang gives the example of the phlogiston theorists' explanation of the similarity of the metals, which appealed to their shared phlogiston. Though metals do not contain hydrogen, the reminder of the problem is useful. Moreover, if retaining phlogiston would have reminded oxygen theorists of various unsolved problems, such reminders would have counted as a kind of productive interaction between the phlogiston and oxygen theories. Hence, I think Chang is also correct that retaining phlogiston would have likely lead to subsequent productive interactions. 
That said, if the identification with hydrogen was well-entrenched by the early nineteenth century, it's unlikely that retaining phlogiston would have lead to the other benefits that Chang discusses, namely, more rapid progress regarding energy and electricity. There doesn't seem to be any kind of direct path from phlogiston qua hydrogen to these benefits, and so it's likely that they would not have materialized. ${ }^{10}$ There may have been a more indirect path to such benefits, for example, one that took into account various electrochemical phenomena, like the fact that hydrogen is attracted to the negative surface in an electric circuit. However, even if there were such an indirect path, it's not clear that the retention of phlogiston would be needed for following that path, since oxygen theorists could also recognize these electrochemical phenomena. More generally, in order for the retention of phlogiston to have the benefits for which Chang argues, it had to have been possible for chemists working in the early nineteenth century to identify phlogiston with energy and/or electricity. And if my argument in section 3.2 is correct, the identification of phlogiston with hydrogen was so well entrenched that it would have been difficult, but perhaps not impossible, for an identification with electricity, energy, or anything else, to catch on.

Some unaddressed issues still remain. It's possible that the retention of phlogiston, along with its identification with hydrogen, could have brought about some benefits that Chang does not discuss. And it's also possible that retaining phlogiston could have brought about harms. In my view, the retention of phlogiston would most likely have brought about both benefits and harms. In order to see this, a useful starting point is Kirwan's framing of what is at issue in the opposition between the phlogiston theorists and the oxygen theorists:

The controversy is therefore at present confined to a few points, namely, whether the inflammable principle be found in what are called phlogisticated acids, vegetable acids, fixed air, sulphur, phosphorus, sugar, charcoal, and metals. (1789, pp. 6-7)

Kirwan held that the inflammable principle (i.e., phlogiston, or hydrogen) is a constituent of all of these substances, and we can inquire into the benefits and harms of retaining a view like this.

\footnotetext{
${ }^{10}$ Mauskopf (2013, p. 625$)$ and Kusch $(2015$, p. 75$)$ both make a similar evaluation when they claim that Kirwan's phlogiston theory, which identified phlogiston with hydrogen, did not have the potential to bring about the benefits that Chang discusses.
} 
As for the benefits of retention, acids do contain hydrogen, and so the expectations of phlogiston theorists like Kirwan would have paid off. ${ }^{11}$ It's difficult not to conclude that the oxygen theory of acidity retarded progress in determining the composition of acids. It encouraged chemists to look for oxygen (the principle of acidity) in acids like muriatic acid (hydrochloric acid, $\mathrm{HCl}$ ) and prussic acid (hydrocyanic acid, $\mathrm{HCN}$ ) that do not contain it. In contrast, phlogiston theorists were in a better position to grasp the nature of such acids. A case in point is Scheele, who was the first to isolate chlorine by decomposing muriatic acid, and who held that the components of that acid are chlorine and phlogiston (1931/1774, pp. 29-30). In the course of presenting his own results on muriatic acid, Davy claims that Scheele's view "may be considered as an expression of facts," while the oxygen theory "rests in the present state of our knowledge, upon hypothetical grounds" (1810b, p. 237). Perhaps if some kind of phlogiston theory had been more widely held, and the oxygen theory had been less widely held, chemists would have determined the composition of muriatic acid and prussic acid more quickly than they, in fact, did. I take it that this is a plausible benefit of retaining phlogiston.

Although some phlogiston theorists may have been in a better position to grasp the nature of acids that do not contain oxygen, it's debatable whether the theories of acidity that phlogiston theorists offered were much of an improvement over Lavoisier's oxygen theory. Kirwan's theory of acidity is a kind of hybrid phlogistonist/oxygenist theory. According to his theory, the principle of acidity is fixed air, which we know as carbon dioxide $\left(\mathrm{CO}_{2}\right)$, but which Kirwan held to be a compound of phlogiston and oxygen (1789, pp. $39,78,80)$. And on the phlogistic theory that Davy entertains in his 1807 Bakerian lecture, acids are compounds of certain unknown bases and water (1808a, p. 33). Since both water and Kirwan's fixed air contain oxygen, there is a sense in which these theories are just as misguided as Lavoisier's oxygen theory of acidity.

That said, there's also a sense in which these phlogiston theories of acidity are much closer to the truth than the oxygen theory. Since both water and Kirwan's fixed air also contain hydrogen, these theories entail that acids contain hydrogen. And based on two of our three current definitions of acidity, namely, the Arrhenius definition and the Brønsted-Lowry definition,

\footnotetext{
${ }^{11} \mathrm{~A}$ caveat is in order here-Arrhenius acids and Brønsted-Lowry acids contain hydrogen, while Lewis acids needn't.
} 
it is hydrogen ions, and not oxygen, that play an essential role in acids. It's admittedly a long shot to conclude that retaining phlogiston would have enabled chemists to recognize this essential role more quickly than they, in fact, did. But it's at least worth considering, and it may represent another potential benefit of retaining phlogiston.

As for the harms of retention, fixed air, sulphur, phosphorus, charcoal, and the metals do not contain hydrogen, and so the expectations of phlogiston theorists would have been frustrated. Just as the oxygen theory retarded progress regarding the composition of acids, it's likely that retaining phlogiston would have retarded progress regarding the composition of these substances. After all, it would have guided chemists to continue to attempt to isolate the hydrogen that these substances purportedly contain. It's plausible, then, that eliminating phlogiston actually benefited the scientific investigation into the composition of these substances.

\section{The Rationality of Eliminating/Retaining Phlogiston}

Now that we've seen that the retention of phlogiston would likely have brought about both benefits and harms, we can examine the issue of rationality. To be sure, these are distinct issues. An evaluation of the rationality of deciding whether to retain phlogiston in the early nineteenth century must be independent of any subsequent benefits and harms of doing so, which were largely unknown at the time of the decision. That said, in this section, I'll draw on some of the historical details from my discussion of the benefits and harms of retention in order to argue that it was rational for chemists to eliminate phlogiston, and that it also would have been rational for them to retain it. But first, I'll discuss what Chang has to say regarding the rationality of the Chemical Revolution, since I'll be concerned to replace his view of rationality with my own.

\subsection{Chang on the Rationality of the Chemical Revolu- tion}

According to Chang (2012, p. 51), if it was rational for chemists to abandon phlogiston and embrace Lavoisier's oxygen theory, then Chang's own 
claim that phlogiston suffered a premature death would be invalidated. For this reason, he devotes a fair amount of discussion to the rationality of the Chemical Revolution. He begins by making the following three points, which admittedly fall short of a comprehensive theory of rationality:

Firstly, rationality is not a matter of truth; rather, rationality is about good ways of making judgments and decisions, given what one knows or believes at the time. ... Secondly, rational thinking or discourse follows some rules or methods that are agreed within the relevant community, to the extent that there is conscious deliberation at all. Thirdly, the minimal condition of rationality is instrumental: at least, a rational action must either achieve some stated aim of the agent, or at least be intended by the agent as contributing toward a certain aim. $(2012 \text {, p. 51) })^{12}$

In my view, these points suffice for the purposes of his discussion, and I'll adopt them in what follows.

Although Chang holds that the Chemical Revolution "was a fairly rational affair," there was an element of irrationality, which he locates "not in the refusal of some chemists to go along with Lavoisier, but in the readiness of too many others to do so" (2012, p. 56). He considers, and ultimately rejects, a number of arguments in the literature that purport to show that such a conversion was rational (2010, pp. 49-61; 2012, pp. 51-56). On Chang's understanding of rationality, in order to sustain the claim that phlogiston was killed prematurely, it cannot be the case that it was rational for these chemists to abandon phlogiston and convert. ${ }^{13}$ Chang's overall view of rationality thus entails that the rationality of eliminating phlogiston precludes the rationality of retaining it, and vice versa. Unless Chang had this view of rationality in mind, he wouldn't be concerned with objecting to various arguments purporting to show the rationality of abandoning phlogiston and converting to the oxygen theory. It's also worth noting that the three points with which Chang prefaces his discussion do not entail his overall view of

\footnotetext{
${ }^{12}$ These latter two points correspond to the deontological and consequentialist conceptions of rationality that are often discussed in the literature on that topic. See Samuels, Stich, and Faucher (2004, p. 166) for a good introduction to these two conceptions.

${ }^{13}$ Kusch (2015, p. 74) sees the issue in quite the same way, and claims that Chang's argument requires him to show that it was irrational for chemists working in the late eighteenth century to abandon phlogiston.
} 
rationality. Chang's view of rationality is one that I wish to question, and ultimately replace, in what follows, and I now turn to that task.

\subsection{Eliminating and Retaining Phlogiston are Both Ra- tional}

My own view is that it was rational to eliminate phlogiston, and it also would have been rational to retain it. I'll now attempt to show why both elimination and retention would have been rational, and in doing so, I'll once again make use of the identification of phlogiston with hydrogen.

I'll consider the rationality of elimination first. Once again, Kirwan's (1789, pp. 6-7) account of the controversy will serve as a useful way to frame my discussion. As I've already noted above, Kirwan held that fixed air (carbon dioxide, $\mathrm{CO}_{2}$ ), sulphur, and the metals all contain hydrogen. By 1791, Kirwan's failure to isolate the hydrogen that he presumed these substances to contain led him to abandon his phlogiston theory:

I know of no single clear decisive experiment by which one can establish that fixed air is composed of oxygen and phlogiston, and without this proof it seems to me impossible to prove the presence of phlogiston in metals, sulphur or nitrogen ... (quoted in Partington, 1961, p. 664)

It would surely be rational for chemists to eliminate phlogiston for the reasons that Kirwan cites. More specifically, if phlogiston qua hydrogen was supposed to be a shared component of these substances, as the evidence against the existence of hydrogen in these substances grew, it would have been rational to eliminate phlogiston while retaining hydrogen.

While I take it that the identification of phlogiston with hydrogen supports the rationality of eliminating phlogiston, I also see a way in which this same identification supports the rationality of retaining it. In short, the basic idea is that, insofar as it was rational for chemists to retain hydrogen, it would have been rational for them to retain phlogiston. To be sure, the lack of phlogiston qua hydrogen in the substances discussed in the previous paragraph would have frustrated the expectations of phlogiston theorists. But these substances are only a subset of the substances that Kirwan mentions in his account of the controversy. He also mentions acids and sugar, which do contain hydrogen. Phlogiston theorists needn't have held that all of the substances that Kirwan lists must contain hydrogen in order for the controversy 
to be settled in their favor. It would have been rational for them to retain phlogiston, and conclude that it was somewhat different from what they had initially theorized. They might have even gotten to work on determining the role of phlogiston in acids, which could have brought about the benefits I discussed in section 3.3.

If this conclusion seems implausible, it's worth recalling some of the points that Chang makes regarding oxygen, which I discussed in section 2.2. In particular, chemists retained oxygen even after they discovered that it is not the principle of acidity, that it is not the sole supporter of combustion, and that the heat and light that result from combustion are not due to the decomposition of oxygen gas into oxygen base and caloric. These discoveries represented a significant departure from Lavoisier's oxygen theory, and yet it was still rational for chemists to retain oxygen. In that case, it would also have been rational for chemists to retain a modified form of phlogiston after acknowledging that various discoveries had shown that their initial theories were, in various respects, incorrect.

My attempt to justify the rationality of retaining phlogiston differs from Chang's, though I do think that I can appeal to one of Chang's insights in order to strengthen my argument. In section 2.2, I discussed Chang's idea that the retention of oxygen was justified by the operations chemists used to produce it. And given that phlogiston theorists also had operations for producing phlogiston, Chang concludes that there was no more reason to eliminate phlogiston than there was to eliminate oxygen. One issue with Chang's proposal is that he considers a number of distinct and mutually incompatible phlogiston theories, including Kirwan's 'inflammable air' theory, Priestley's 'electric fluid' theory, and Cavendish's 'elementary water' theory. In that case, determining the set of operations for producing phlogiston may prove difficult. But if I am right that, by the early nineteenth century, the identification of phlogiston with hydrogen was well entrenched, then we would have a way of determining the operations by which chemists at the time produced phlogiston - they are just the same operations by which they produced hydrogen. In that case, Chang's operational justification for retaining phlogiston applies even more forcefully once one takes into account the well-entrenched nature of the identification of phlogiston with hydrogen.

One may object that what I've pointed to here are actually considerations that must be weighed in the course of determining whether elimination or retention is rational, rather than considerations that show both decisions to be rational. There may be reasons in favor of elimination, and reasons in 
favor of retention. But rationality requires weighing these reasons against one another in order to determine the optimal decision. It may be the case that such reasons are, indeed, equally good, which allows for the possibility that the two decisions can be equally rational. But if this is, indeed, the case, then perhaps I need to do more in order to show that the reasons on each side are equally good.

In order to respond to this objection, it's sufficient to point out that there may be no privileged perspective from which one can weigh these reasons. As Chang emphasizes, rationality is, at least in part, about making good decisions based on what one believes. Furthermore, as I'll now argue, the outcome of weighing these reasons depends on the beliefs of those who weigh them. To see this, we can consider the following two beliefs:

(1) Phlogiston is found in acids.

(2) Phlogiston is found in metals.

And we'll consider two fictional early-nineteenth-century phlogiston theorists (chemist $A$ and chemist $B$ ), while keeping in mind that the identification of phlogiston with hydrogen was, by this point, well entrenched.

Suppose that chemist $A$ and chemist $B$ both believe (1) and (2), but they differ from one another regarding the beliefs that they are likely to abandon in light of new evidence. Chemist $A$ is more willing to abandon (2) than to abandon (1), and in that sense, takes phlogiston's role in acids to be more central than its role in metals. In contrast, chemist $B$ is more willing to abandon (1) than to abandon (2), and in that sense, takes phlogiston's role in metals to be more central than its role in acids. Now suppose that both discover that acids, but not metals, contain hydrogen. Given their beliefs, the reasons in favor of retaining phlogiston will appear stronger to chemist $A$ than to chemist $B$. Moreover, the reasons in favor of eliminating phlogiston will appear stronger to chemist $B$ than to chemist $A$. Hence, given their beliefs, we can see that, if chemist $A$ were to decide to retain phlogiston, and chemist $B$ to eliminate it, both decisions would be rational.

It may be objected that this conclusion merely shows that we must move from considering the rationality of decisions to the rationality of beliefs. Once we can show that one chemist's set of beliefs is more rational than the other's, we can show that one decision is more rational than the other. However, in the case under consideration, this objection does not have much force since, given the state of chemistry in the early nineteenth century, both sets of 
beliefs were rational. We can grasp this point by reference to Davy's work. Davy entertained both (1) and (2), and even if he didn't believe either, the fact that he entertained both shows that, at the time, (1) and (2) were live possibilities. It's therefore difficult to convict either chemist $A$ or chemist $B$ of irrationality on the basis of having these beliefs. It's also difficult to say that it would have been irrational to have a stronger belief in (2) than in (1) or vice versa. And since both sets of beliefs were rational, we cannot appeal to those beliefs in order to argue that one decision would have been less rational than the other.

At this point, I'm in a position to state my conclusions regarding the rationality of retaining and eliminating phlogiston. Both decisions were rational, not because chemists lacked decisive empirical evidence, but because what looked to one chemist like decisive evidence for elimination may not have looked decisive from the perspective of some other chemist. When confronted with the same set of experimental results, one chemist could have seen decisive reasons for eliminating phlogiston, while another could have seen decisive reasons for concluding that phlogiston, much like oxygen, is very different from what chemists had initially theorized. Hence, at the level of individual chemists, it was rational for them to eliminate phlogiston, and it also would have been rational for them to retain it. When it comes to the community of chemists more generally, I take it that it was rational for them, as a whole, to eliminate phlogiston. But it's also possible that those individual chemists in favor of retaining phlogiston could have reached the critical mass required for the community, as a whole, to retain it, and I see no reason why it would be irrational of them to do so. It also would have been rational for the community to embody the kind of pluralism for which Chang argues, according to which some chemists would develop the oxygen theory, and others would develop phlogiston theories or hybrid theories that employ both oxygen and phlogiston. In short, when it comes to phlogiston, both retention and elimination would have been rational.

\section{$5 \quad$ Scientific Rationality More Generally}

I'll now make some brief remarks about how the arguments that I've presented bear on the issue of scientific rationality more generally. If those arguments are correct, then we must admit that, when scientists are faced

with a decision between retaining and eliminating a given entity, it may be 
the case, at least sometimes, that both decisions are rational. Rationality alone may not dictate whether scientists ought to respond to some particular empirical results by eliminating an entity, or by retaining it in some modified form. It's not always the case that one decision is rationally required, while the other is forbidden. Both decisions may be rationally permissible, and an adequate account of scientific rationality must be able to accommodate such cases.

I won't attempt to develop an account of scientific rationality that accommodates such cases. Instead, I'll discuss a couple of extant views of rationality, due to Bas van Fraassen (1989) and P. D. Magnus (2014), that, in my view, hold some promise for accommodating such cases. Both views are broadly pragmatist in nature, and both hold that rationality concerns what is permitted, as opposed to what is required. On van Fraassen's (1989, pp. 171-172) view, "what it is rational to believe includes anything that one is not rationally compelled to disbelieve." And since distinct sets of beliefs can be consistent with this prescription, van Fraassen's account allows for the possibility that "rational persons with the same evidence can still disagree in their opinion" (1989, p. 175). In a similar vein, Magnus's view "allows for some people to rationally believe $P$ and others to rationally believe $\sim P$ " (2014, p. 134). Magnus can thus acknowledge that "rationality must allow agents in comparable circumstances to come to different beliefs; that is, epistemology must be permissive" (2014, p. 132). Both views thus allow for the possibility that rational scientists could have disagreed regarding, say, their beliefs in the existence of phlogiston. And to that extent, both views hold some promise for accommodating cases in which retention and elimination are both rational decisions.

There are, however, two respects in which these views would need to be developed further in order to fully accommodate such cases. First of all, both views concern the rationality of beliefs, and they would need to be extended to cover the rationality of decisions, like the decision between retaining and eliminating a given entity. Secondly, both views concern individual rationality as opposed to collective rationality, and in order to accommodate my conclusions about the rationality of the community of chemists as a whole, it's necessary to say something about collective rationality. Magnus is not silent on this issue - he puts forward his view in an attempt to show that collective rationality does not require scientists to violate individual rationality. He begins with the idea that collective rationality may require scientists to adopt different beliefs in the same circumstances. While some philosophers 
hold that collective rationality thus requires scientists to violate individual rationality, ${ }^{14}$ Magnus argues that it can be rational for individual scientists to adopt different beliefs in the same circumstances. It would involve a further step to draw the same conclusion about collective rationality, and show that, say, different communities (perhaps sub-communities or counterfactual communities) can rationally adopt different beliefs, or make different decisions, in the same circumstances. Taking this further step would be necessary in order to accommodate cases like the one I discussed. That said, I suspect that, with a bit of work, a view of the kind that Magnus and van Fraassen defend can be extended to decisions and to collective rationality.

\section{Conclusion}

My primary goal in this chapter has been to argue that it was rational to eliminate phlogiston, but that it also would have been rational to retain it. In doing so, I framed my arguments as a response to Chang's work on the Chemical Revolution. I also attempted to show that the identification of phlogiston with hydrogen, as made by a number of prominent phlogiston theorists in the late eighteenth century, became rather well-entrenched by the early nineteenth century. I employed this identification in order to evaluate the benefits and harms of retaining and eliminating phlogiston, respectively, and in order to evaluate the rationality of these two decisions. And I concluded that, more generally, scientific rationality concerns what is permissible, as opposed to what is required.

Acknowledgements: Thanks to Tzu-Wei Hung, Timothy Lane, and the participants of the 2014 IEAS Conference on Reason and Rationality for stimulating my thinking on the topic of rationality; and to David Jacobs, Derek Leben, and Karen Yan for comments on previous drafts. Much of the research for this chapter was completed during my time as a postdoctoral fellow at the Institute of European and American Studies at Academia Sinica, and so I thank the institute, and especially my sponsor, Jih-Ching Ho.

\footnotetext{
${ }^{14}$ Magnus's examples of such philosophers are Kitcher (1990) and Zollman (2010).
} 


\section{References}

Bergman, Torbern (1785). A dissertation on elective attractions. John Murray, Edinburgh.

Boantza, Victor (2008). The phlogistic role of heat in the Chemical Revolution and the origins of Kirwan's 'ingenious modifications ... into the theory of phlogiston'. Annals of Science, 65(3):pp. 309-338.

Bolton, Henry Carrington (Ed.) (1892). Scientific correspondence of Joseph Priestley: Ninety-seven letters addressed to Josiah Wedgwood, Sir Joseph Banks, Capt. James Keir, James Watt, Dr. William Withering, Dr. Benjamin Rush, and others. Collins Printing House, New York.

Cavendish, Henry (1766). Three papers, containing experiments on factitious air. Philosophical Transactions, 56:pp. 141-184.

- (1784). Experiments on air. Philosophical Transactions of the Royal Society of London, 74:pp. 119-153.

Chang, Hasok (2009). We have never been whiggish (about phlogiston). Centaurus, 51(4):pp. 239-264.

- (2010). The hidden history of phlogiston: How philosophical failure can generate historiographical refinement. HYLE-International Journal for Philosophy of Chemistry, 16(2):pp. 47-79.

- (2011). The persistence of epistemic objects through scientific change. Erkenntnis, 75(3):pp. 413-429.

- (2012). Is water $\mathrm{H}_{2} \mathrm{O}$ ? Evidence, realism and pluralism. Springer, Dordrecht.

Davy, Humphry (1808a). The Bakerian Lecture [for 1807]: On some new phenomena of chemical changes produced by electricity, particularly the decomposition of the fixed alkalies, and the exhibition of the new substances which constitute their bases; and on the general nature of alkaline bodies. Philosophical Transactions of the Royal Society of London, 98:pp. 1-44. 
- (1808b). Electro-chemical researches, on the decomposition of the earths; with observations on the metals obtained from the alkaline earths, and on the amalgam procured from ammonia. Philosophical Transactions of the Royal Society of London, 98:pp. 333-370.

- (1809). The Bakerian Lecture [for 1808]: An account of some new analytical researches on the nature of certain bodies, particularly the alkalies, phosphorus, sulphur, carbonaceous matter, and the acids hitherto undecompounded; with some general observations on chemical theory. Philosophical Transactions of the Royal Society of London, 99:pp. 39-104.

- (1810a). The Bakerian Lecture for 1809. On some new electrochemical researches, on various objects, particularly the metallic bodies, from the alkalies, and earths, and on some combinations of hydrogene. Philosophical Transactions of the Royal Society of London, 100:pp. 16-74.

- (1810b). Researches on the oxymuriatic acid, its nature and combinations; and on the elements of the muriatic acid. With some experiments on sulphur and phosphorus, made in the laboratory of the Royal Institution. Philosophical Transactions of the Royal Society of London, 100:pp. 231-257.

Davy, John (1836). Memoirs of the life of Sir Humphry Davy, volume 1. Printed for Longman, Rees, Orme, Brown, Green, \& Longman, London.

Gibbes, George Smith (1809). A phlogistic theory ingrafted upon M. Fourcroy's philosophy of chemistry. W. Meyler and Son, Bath.

Kinzel, Katherina (2015). State of the field: Are the results of science contingent or inevitable? Studies In History and Philosophy of Science, 52:pp. $55-66$.

Kirwan, Richard (1782). Continuation of the experiments and observations on the specific gravities and attractive powers of various saline substances. Philosophical Transactions of the Royal Society of London, 72:pp. 179-236.

- (1789). An essay on phlogiston and the constitution of acids. J. Johnson, London, 2nd edition.

Kitcher, Philip (1990). The division of cognitive labor. The Journal of Philosophy, 87(1):pp. 5-22. 
Klein, Ursula (2015). A Revolution that never happened. Studies In History and Philosophy of Science, 49:pp. 80-90.

Kuhn, Thomas S. (2012/1962). The structure of scientific revolutions. University of Chicago Press, Chicago, 50th anniversary edition.

Kusch, Martin (2015). Scientific pluralism and the Chemical Revolution. Studies In History and Philosophy of Science, 49:pp. 69-79.

Lavoisier, Antoine Laurent (1965/1789). Elements of chemistry. Dover, New York.

Magnus, P. D. (2014). Science and rationality for one and all. Ergo, 1(5):pp. 129-138.

Mauskopf, Seymour H. (2013). Historicizing $\mathrm{H}_{2} \mathrm{O}$. Studies In History and Philosophy of Science, 44(4):pp. 623-630.

McEvoy, John G. (1997). Positivism, whiggism and the Chemical Revolution: A study in the historiography of chemistry. History of Science, 35:pp. 1-33.

Partington, J. R. (1961). A history of chemistry, volume 3. Macmillan, London.

Priestley, Joseph (1802). Observations and experiments relating to the pile of Volta. A Journal of Natural Philosophy, Chemistry, and the Arts, by William Nicholson, 1:pp. 198-204.

Radick, Gregory (2008). Introduction: Why what if? Isis, 99(3):pp. 547-551.

Reiss, Julian (2009). Counterfactuals, thought experiments, and singular causal analysis in history. Philosophy of Science, 76(5):pp. 712-723.

Samuels, Richard, Stich, Stephen, and Faucher, Luc (2004). Reason and rationality. In Ilkka Niiniluoto, Matti Sintonen, and Jan Woleński (Eds.), Handbook of epistemology, (pp. 131-179). Springer, Netherlands.

Scheele, Carl Wilhelm (1780). Chemical observations and experiments on air and fire, with a prefatory introduction by Torbern Bergman; translated from the German by J. R. Forster; to which are added notes by Richard Kirwan; with a letter to him from Joseph Priestley. J. Johnson, London. 
- (1931/1774). On manganese or magnesia; and its properties. In The collected papers of Charles Wilhelm Scheele, translated from the Swedish and German originals by Leonard Dobbin, (pp. 17-49). G. Bell and Sons, London.

Siegfried, Robert (1964). The phlogistic conjectures of Humphry Davy. Chymia, 9:pp. 117-124.

- (1988). The Chemical Revolution in the history of chemistry. Osiris, 4:pp. $34-50$.

Soler, Léna (2008). Are the results of our science contingent or inevitable? Studies In History and Philosophy of Science, 39(2):pp. 221-229.

Stewart, John (2012). The reality of phlogiston in Great Britain. HYLEInternational Journal for Philosophy of Chemistry, 18(2):pp. 175-194.

van Fraassen, Bas C. (1989). Laws and symmetry. Clarendon Press, Oxford.

Zollman, Kevin J. S. (2010). The epistemic benefit of transient diversity. Erkenntnis, 72(1):pp. 17-35. 